\title{
ON MERGER PROFITABILITY IN A COURNOT SETTING
}

\author{
Ramón Faulí-Oller
}

WP-AD 97-03

Correspondencia: Universidad de Alicante, Facultad de Ciencias Económicas. Dpto. Fundamentos de Análisis Económico, Ctra. San Vte. del Raspeig, s/n, 03071 ALICANTE, E-mail: fauli@merlin.fae.ua.es / Tel.: 34965903400 / Fax: 34965903898.

Editor: Instituto Valenciano de Investigaciones Económicas, S.A.

First Edition February 1997.

Depósito Legal: V-496-1997

ISBN: 84-482-1435-8

IVIE working papers offer in advance the results of economic research under way in order to encourage a discussion process before sending them to scientific journals for their final publication

\footnotetext{
* This paper is a thoroughly revised version of part of Chapter IV of my Ph.D. Dissertation written under the supervision of Xavier Vives. I also benefitted from the supervision of Jacques Crémer while I was visiting the GREMAQ. I wish to thank Jacques Crémer, Josep Peris and Xavier Vives for their helpful comments. Financial support through contract ERBCHBGCT940681 from the Human Capital and Mobility Programme, from the Spanish Ministry of Education through CICYT grant PB93-0679-1 and from the IVIE is gratefully acknowledged.
} 


\section{ON MERGER PROFITABILITY IN A COURNOT SETTING}

\section{Ramon Faulí-Oller}

\section{A B S T R A C T}

In a setting where symmetric firms compete à la Cournot and costs are linear, the degree of concavity is identified as the main determinant of merger profitability. This allows to generalize the results in Salant et al (1983) and Cheung (1992).

KEYWORDS: Mergers; Profitability. 
Salant et al. (1983) showed in the symmetric Cournot model where demand and costs are linear that all mergers with a market share lower than $80 \%$ are unprofitable. It remained to check to what extent the result depended on the linearity of demand. Cheung (1992) showed that for demands satisfying that the marginal revenue of the industry is decreasing, the minimal market share for a merger to be profitable is $50 \%$.

I address the question why the above thresholds differ. I show that profitability of mergers depends on the degree of concavity of demand: the greater the degree of concavity the lower the profitability of a merger. Therefore, Cheung's threshold was lower than Salant et al's, because he allowed for strictly convex demands. If he had enlarged the set of demands considered by Salant et al.(1983) by allowing only for concave demands the threshold would not have changed. The main result of the paper is a generalization of this result. Sets of demands are characterized by fixing a lower bound of the degree of concavity. Then, I show that the minimal market share is increasing in this lower bound.

Corchón and González-Maestre (1994) demonstrated the importance of the degree of concavity in a model where firms could create independently managed divisions. As divisionalization can be seen as the opposite process to mergers they got that divisionalization is more profitable the greater the degree of concavity. 
Assume we have $\mathrm{N}$ firms competing à la Cournot, where $2 \leq \mathrm{N} \leq \hat{N}$, and $\hat{N}$ is as large as we want but finite. They all have the same constant marginal cost $(c>0)$ and sell the same product. The inverse demand function $P(X)$ (price as a function of quantity $X$ ) is twice-continuously differentiable and $\mathrm{P}^{\prime}(\mathrm{X})<0$. Demand at price $\mathrm{c}$ is positive but finite and satisfies:

$$
2 P^{\prime}(X)+P^{\prime \prime}(X) X<0
$$

(1) is equivalent to: $\beta(X)>-2$, where $\beta(X)=\frac{P^{\prime \prime}(X) X}{P^{\prime}(X)}$ is defined as the degree of concavity of demand.

We consider the possibility that a group of firms merge. Like non-merging firms, the merging entity produces at marginal cost $\mathrm{c}$ and behaves à la Cournot. Cheung (1992) shows that the equilibrium is unique and symmetric. Equilibrium sales $(X)$ satisfy:

$$
P^{\prime}(X) \frac{X}{n}+P(X)-c=0
$$

The previous equation defines implicitly the equilibrium sales as a function of the number of independent firms $(\mathrm{X}(\mathrm{n}))$. Following Salant et al. (1983) and Cheung (1992), I will assume that the number of firms can be treated as a continuous variable. This must be regarded as an approximation which sharpens the results. Differentiating (2) with respect to $n$ we have:

$$
P^{\prime \prime} X^{\prime} \frac{X}{n}+\frac{P^{\prime} X^{\prime}}{n}-\frac{P^{\prime} X}{n^{2}}+P^{\prime} X^{\prime}=0
$$

Rearranging we obtain the proportional increase in output due to a marginal increase in the number of firms: 


$$
\frac{X^{\prime}}{X}=\frac{1}{n(\beta(n)+n+1)}
$$

Individual profits of firms in equilibrium are given by:

$$
\pi(n)=\frac{|P(X(n))-c| X(n)}{n}
$$

Differentiating with respect to $n$ we have:

$$
\pi^{\prime}(n)=P^{\prime} X^{\prime} \frac{X}{n}+X^{\prime} \frac{P-c}{n}-\frac{(P-c) X}{n^{2}}
$$

Rearranging we have the proportional increase in profits due to a marginal increase in the number of firms (n):

$$
\frac{\pi^{\prime}(n)}{\pi(n)}=\frac{X^{\prime}}{X}\left(\frac{P^{\prime} X}{(P-c)}+1\right)-\frac{1}{n}
$$

Using (2) and (3) leads to:

$$
-\frac{\pi^{\prime}(n)}{\pi(n)}=\frac{n-1}{n(\beta(n)+n+1)}+\frac{1}{n}
$$

By integrating the previous expression we obtain the following,

$$
\int_{N-k}^{N}-\frac{\pi^{\prime}(n)}{\pi(n)} d n=\ln \left[\frac{\pi(N-k)}{\pi(N)}\right]=\int_{N-k}^{N}\left(\frac{n-1}{n(\beta(n)+n+1)}+\frac{1}{n}\right) d n .
$$

Then we have that the proportional increase in profits due to a merger of $k+1$ firms amounts to,

$$
\frac{\pi(N-k)}{\pi(N)}=\operatorname{Exp}\left[\int_{N-k}^{N}\left(\frac{n-1}{n(\beta(n)+n+1)}+\frac{1}{n}\right) d n\right] .
$$


Definition 1: A merger of $k+1$ firms is said to be profitable if $\frac{\pi(N-k)}{\pi(N)} \geq k+1$.

Define $\mathrm{F}(\mathrm{b}, \mathrm{N}, \mathrm{k})=1\left(\frac{N}{N-k}\right)^{\left(\frac{b}{1+b}\right)}\left(\frac{N+b+1}{N-k+b+1}\right)^{\left(\frac{2+b}{1+b}\right)}$. If the degree of concavity is constant $\mathrm{N}$

$(\beta(n)=b)$, then we have that $\frac{\pi(N-k)}{\pi(N)}=\operatorname{Expl} \int_{N-k}\left(\frac{n-1}{n(b+n+1)}+\frac{1}{n}\right) d n I=F(b, N, k)$. If the degree of concavity is not constant but it is not lower than $b$, we have that $\frac{\pi(N-k)}{\pi(N)} \leq F(b, N, k)$.

Both results play a central role in the proof of Proposition I.

Before stating the general result, I show that the results in Salant et al.(1983) and Cheung (1992) can be obtained from my calculations. The former considers demands that satisfy $\beta(X)=0$ and the latter demands that satisfy $\beta(X)>-2$. If $\beta(X)=0$, then $\frac{\pi(N-k)}{\pi(N)}=F(0, N, k)$. Therefore, if $\mathrm{F}(0, \mathrm{~N}, \mathrm{k})=\left(\frac{\mathrm{N}+1}{\mathrm{~N}-\mathrm{k}+1}\right)^{2}<\mathrm{k}+1$, mergers are not profitable. This is equivalent to equation (3') in Salant et al (1983). If $\beta(X)<-2$, then $\frac{\pi(N-k)}{\pi(N)}<F(-2, N, k)$. Therefore, if $F(-$ $2, N, k)=\left[\frac{N}{N-k}\right]^{2} \leq k+1$, then mergers are not profitable. This is the same condition studied in Cheung (1992).

Definition 2: Given a set of demands, the minimal market share is the supremum of the numbers $\mathrm{j}$ satisfying that in any market such that the demand belongs to the set, any merger with a market share lower than $\mathrm{j}$ is unprofitable.

Proposition I: Assume that $\frac{\mathrm{P}^{\prime \prime}(\mathrm{X}) \mathrm{X}}{\mathrm{P}^{\prime}(\mathrm{X})} \geq \mathrm{b}>-2$ for any $\mathrm{X}$. The minimal market share is increasing in $b$.

$\left.{ }^{l} \mathrm{~F}(-1, \mathrm{~N}, \mathrm{k})=\left[\frac{\mathrm{N}}{\mathrm{N}-\mathrm{k}}\right]^{2} \operatorname{Expl} \frac{1}{\mathrm{~N}}-\frac{1}{\mathrm{~N}-\mathrm{k}}\right]$. 
Proof: Appendix I shows that there exists a number $k(\mathrm{~N}, \mathrm{~b}) \in(0, \mathrm{~N}-1)$ such that:

$$
\begin{gathered}
F(N, k, b)<k+1 \text { if } 0<k<k(N, b) \\
F(N, k, b)=k+1 \text { if } k=k(N, b) \\
F(N, k, b)>k+1 \text { if } k(N, b)<k<N-1 .
\end{gathered}
$$

Define $f(N, b)=\frac{k(N, b)+1}{N}$. Given $N$, a merger of $k+1$ firms such that $\frac{k+1}{N}<f(N, b)$ is unprofitable, because $\frac{\pi(N-k)}{\pi(N)} \leq F(N, k, b)<k+1$, given that $k<k(N, b)$. Furthermore, if demand satisfies that $\frac{P^{\prime \prime}(X) X}{P^{\prime}(X)}=b$ for any $X$, a merger of $k(N, b)+1$ firms with market share $f(N, b)$ is profitable because $\frac{\pi(N-k(N, b))}{\pi(N)}=F(N, k(N, b), b)=k(N, b)+1$. Therefore $f(N, b)$ is the supremum of the numbers $\mathrm{j}$ satisfying that in any market with $\mathrm{N}$ firms such that the demand belongs to the set, any merger with a market share lower than $\mathrm{j}$ is unprofitable. The minimal market share requires that this condition be satisfied for any $\mathrm{N}$.

${ }_{N}^{\operatorname{Inf}} f(N, b)$ exists because $f(N, b)$ is bounded and the domain of $N$ is compact. $m(b)={ }_{N}^{\operatorname{Inf}} f(N, b)$ is the minimal market share, because:

a.- Any merger with a market share lower than $m(b)$ is unprofitable, because $m(b) \leq f(N, b)$ for any $N$.

b.- A number $g$ greater than $m(b)$ does not satisfy the condition above. For definition of infimum exist $N$ such that $m(b) \leq f(N, b)<g$. Furthermore, in a market with $N$ firms and demand such that $\frac{P^{\prime \prime}(X) X}{P^{\prime}(X)}=b$ for any $X$, a merger with a market share of $f(N, b)$ is profitable.

If $b_{1}<b_{2}$, we have that $F\left(N, k, b_{2}\right)<F\left(N, k, b_{1}\right)$. This implies that $k\left(N, b_{1}\right)<k\left(N, b_{2}\right)$. Then $\mathrm{f}\left(\mathrm{N}, \mathrm{b}_{1}\right)<\mathrm{f}\left(\mathrm{N}, \mathrm{b}_{2}\right)$ and we have that $\mathrm{m}\left(\mathrm{b}_{1}\right) \leq \mathrm{m}\left(\mathrm{b}_{2}\right)$. 


\section{Appendix I.}

Define $g(k)=F(N, k, b)$.

$g^{\prime}(k)=g(k)\left(\frac{N-k-1}{(N-k)(N-k+b+1)}+\frac{1}{N-k}\right)$
$g^{\prime \prime}(k)=g(k)\left(\frac{6(N-k)(N-k+b)+2 b^{2}+b}{(N-k)^{2}(N-k+b+1)}\right)$.

There exists a number $k^{*}(N, b) \in(0, N-1)$ s.t. $g(k(N, b))=k(N, b)+1$, because $g(0)=1,0<g^{\prime}(0)$ $<1$ and $\mathrm{g}(\mathrm{n}-1)>\mathrm{n}$ (monopolizing the industry is always profitable). I show that it is unique by showing that whenever $g^{\prime \prime}(k) \leq 0$, then $g^{\prime}(k)>1$. This follows from the fact that $g^{\prime}(n-1)=g(n-$ 1) $>1$ and $p^{\prime}(k)=-2(N-k)-b<0$, where $p(k)=6(n-k)(n-k+b)+2 b^{2}+b$.

From $0<\mathrm{g}^{\prime}(0)<1$, follows that $\mathrm{F}(\mathrm{N}, \mathrm{k}, \mathrm{b})<\mathrm{k}+1$ if $\mathrm{k}<\mathrm{k}(\mathrm{N}, \mathrm{b})$.

From $g(n-1)>n$, follows that $F(N, k, b)>k+1$ if $k>k(N, b)$. 
$\underline{\text { References. }}$

Cheung, F. K, 1992, "Two remarks on the equilibrium analysis of horizontal merger." Economics Letters 40. 119-123.

Corchón, L.C. and González-Maestre, M, 1994, "On the competitive effects of divisionalization". WP-AD 94-10. A discusión. University of Alicante.

Salant S.W., S. Switzer, and R.J. Reynolds, 1983, "Losses from horizontal merger: the effects of an exogenous change in industry structure on Cournot-Nash equilibrium". Quarterly Journal of Economics. May. 185-199. 